\title{
Synthesis, Electrical and Dielectric Properties of Ca-doped $\mathrm{SrTiO}_{3}$ Ceramics
}

\author{
Ali Mater ${ }^{1}$, Massoud Kahlaoui ${ }^{2 \star}$, Abdewaheb Inoubli ${ }^{2}$, Chaabane Chefi $^{1,2}$ \\ 1. Faculté des Sciences de Bizerte, LR01ES15 Laboratoire de Physique des Matériaux: Structure et Propriétés, Université de \\ Carthage, 7021 Zarzouna, Bizerte, Tunisia \\ 2. Unité des services communs spectromètre de surface, Faculté des Sciences de Bizerte, Université de Carthage, Zarzouna \\ 7021, Tunisia.
}

${ }^{\star}$ Corresponding author: Massoud Kahlaoui, E-mail: kahlaouimessaoud@yahoo.fr.

\section{Abstract}

$\mathrm{Ca}_{\mathrm{x}} \mathrm{Sr}_{1-\mathrm{x}} \mathrm{TiO}_{3}\left(\mathrm{C}_{\mathrm{x}} \mathrm{ST} ; \mathrm{x}=0.2\right.$ and 0.4$)$ powders were elaborated by conventional solid state reaction. Structural and electrical properties were influenced by the $\mathrm{Ca}^{2+}$ doping content. Structural and microstructures properties of the obtained powders were conducted by X-ray diffraction and scanning electron microscopy. The powder were pressed to eight tons into cylindrical pellets and sintered at $1300^{\circ} \mathrm{C}$ for $3 \mathrm{~h}$. The electrical and dielectric properties were measured by two-probe method using HP 4192 Analyzer. The refinement of results showed that the samples were crystallized in the tetragonal with $\mathrm{I} 4 / \mathrm{mcm}$ space group. The highest conductivity was shown for $\mathrm{C}_{0.2} \mathrm{ST}$ sample which equal to $1.21 \times 10^{-4} \mathrm{~S}_{\mathrm{cm}} \mathrm{cm}^{-1}$ at $600{ }^{\circ} \mathrm{C}$. The electrical and dielectric parameters were plotted and discussed as a function of temperature and frequency. These Ca doped perovskite ceramics materials can be used as possible candidate for a wide range of applications in various devices.

Keywords

Ca-doped $\mathrm{SrTiO}_{3}$; Solid state reaction; Perovskite; Conductivity; Permittivity

\section{INTRODUCTION}

Solid oxide fuel cells (SOFC) as one of the most fuel cells technologies has attracted much attention due to their advantages over conventional power generation systems, low pollution, high energy conversion efficiency $(80 \%)$ and fuel adaptability ${ }^{[1]}$. But the main drawback for SOFC is the degradation of their components (electrolyte-electrode) as well as their high cost caused by its high operating temperature. To resolve these 
problems, some researcher lowering the operating temperature of SOFC without decreasing the performance of the cell. Therefore, it is necessary to replace the conventional anode materials by another with adequate performance. Perovskite with the general formula $\mathrm{ABO}_{3}$, exhibit an interesting electrochemical properties as a materials for anode in SOFC. Among the currently used $\mathrm{ABO}_{3}$ peroveskite, the strontium titanate $\mathrm{SrTiO}_{3}$ have attractive much attention as anode materials for SOFC. It can be seen in previous works that the doping by aliovalent substitutions in the A sites of $\mathrm{SrTiO}_{3}$ was effective in improving the catalytic activity, the electrical conductivity and optimize the thermal compatibility ${ }^{[2,3]}$.

This work aimed to prepare calcium strontium titanate perovskite as an SOFC anode material candidate. The structure of the perovskite and its electrical properties were investigated to reveal the influence behavior of the calcium amount on the structure and the electrical properties. In addition, the temperature dependence of the dielectric properties of the synthesized perovskites was studied.

\section{EXPERIMENT}

The $\mathrm{Ca}_{\mathrm{x}} \mathrm{Sr}_{1-\mathrm{x}} \mathrm{TiO}_{3}(\mathrm{x}=0.2$ and 0.4$)$ powders were prepared by the conventional solid state reaction method following the process described in our previous work ${ }^{[4]}$. High pure chemicals precursors such as calcium carbonate $\left(\mathrm{CaCO}_{3}, 99.95 \%\right)$, strontium carbonate $\left(\mathrm{SrCO}_{3}, 99.9 \%\right)$ and titania $\left(\mathrm{TiO}_{2} /\right.$ anatase, $\left.99.97 \%\right)$ from Sigma Aldrich were mixed and ground with ethanol in agate mortar, after that the ground powders were calcined at 1,500 ${ }^{\circ} \mathrm{C}$ for $3 \mathrm{~h}$ to obtain the phase. The identification of phases was carried out using a Bruker D-8 advance $\mathrm{x}$-ray diffractometer $(\mathrm{CuK} \alpha=1.540 \AA)$. The diffraction patterns were collected by step scanning for $2 \theta=20^{\circ}-90^{\circ}$ with a step size of $0.05^{\circ}$. The crystalline phase and cell parameters were measured by the PANalyticalX'Pert High Score Plus program usig method of Rietveld.

The morphology of the cylindrical pellets sintered at $1300^{\circ} \mathrm{C}$ for $3 \mathrm{~h}$ were characterized by scanning electron microscope (SEM), JEOL.JSM-5400.

Complex impedances spectroscopy were measured by two electrode in a frequency range between $5 \mathrm{~Hz}$ and $13 \mathrm{MHz}$ with a signal amplitude of $0.5 \mathrm{~V}$. All measurements were carried out at equilibrium potential at temperatures from $250{ }^{\circ} \mathrm{C}$ to $800{ }^{\circ} \mathrm{C}$. The obtained impedance spectra were then analyzed by the Zview software.

\section{RESULTS AND DISCUSSION}

\subsection{Structural and microstructural characterization}

Fig.1a display the XRD patterns of the $\mathrm{Ca}_{\mathrm{x}} \mathrm{Sr}_{1-\mathrm{x}} \mathrm{TiO}_{3}(\mathrm{x}=0.2$ and 0.4$)\left(\mathrm{C}_{\mathrm{x}} \mathrm{ST}\right)$ solid solutions which were prepared via the solid state reaction method. It can be clearly seen that the $\mathrm{Ca}_{0.2} \mathrm{Sr}_{0.8} \operatorname{TiO}_{3}(\mathrm{x}=0.2)$ powder is single-phased with a tetragonal system and I4/mcm space group (ICSD powder diffraction file No. 23076). And no impurity or secondary phases were detected in all samples. The lattice parameters were found to be $\mathrm{a}=\mathrm{b}=$ $5.4967 \AA$ and $\mathrm{c}=7.7843 \AA$. It can also be seen that the $\mathrm{Ca}_{0.4} \mathrm{Sr}_{0.6} \mathrm{TiO}_{3}(\mathrm{x}=0.2)$ powder is single-phased with an tetragonal system and $(\mathrm{I} 4 / \mathrm{mcm})$ space group. The calculated lattice parameters are $\mathrm{a}=5.4763, \mathrm{~b}=5.4763 \AA$ and $\mathrm{c}=7.722 \AA$. These results are in good agreement with the work of Qun Hui et al. ${ }^{[5]}$. The fitting of the XRD pattern of the $\mathrm{C}_{0.2} \mathrm{ST}$ is shown in Fig.1b. Final R-goodness factors were $\mathrm{R}_{\mathrm{p}}=1.366, \mathrm{R}_{\mathrm{wp}}=1.840$, and $\chi\left(\mathrm{chi}^{2}\right)=$ 0.349 .

The morphology of the $\mathrm{C}_{\mathrm{x}} \mathrm{ST}(\mathrm{x}=0.2$ and 0.4$)$ pellets sintered at $1300{ }^{\circ} \mathrm{C}$ for $3 \mathrm{~h}$ is shown in Fig.2. It can be seen from the Fig.2 a porous $\left(\mathrm{Ca}_{0.2} \mathrm{Sr}_{0.8}\right) \mathrm{TiO}_{3}$ and $\left(\mathrm{Ca}_{0.4} \mathrm{Sr}_{0.6}\right) \mathrm{TiO}_{3}$ pellets with a continuous and open pores. The 
average size of the grains was found to be less than 2.5 microns.

Fig.1a

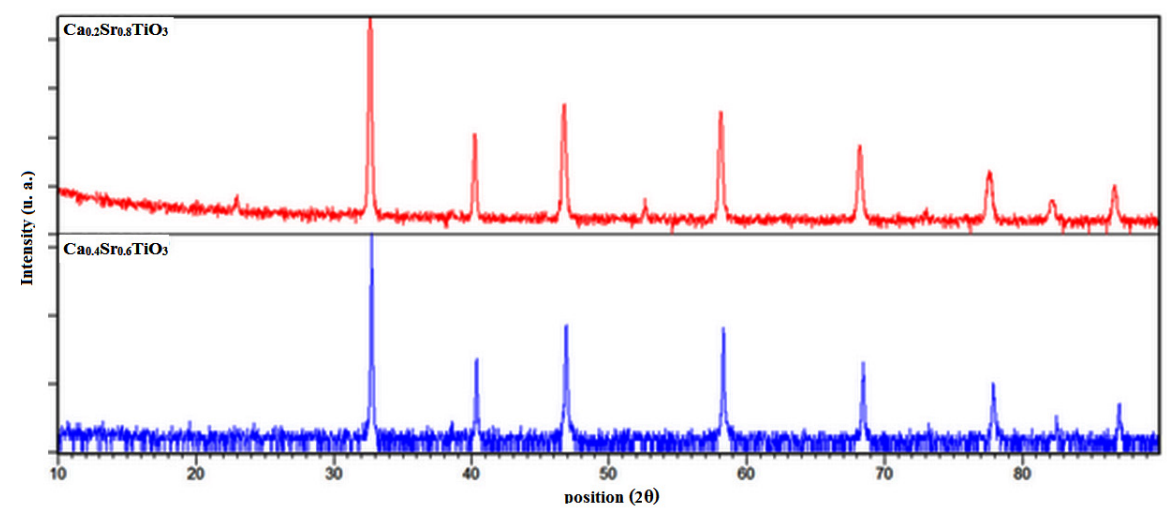

Fig.1b

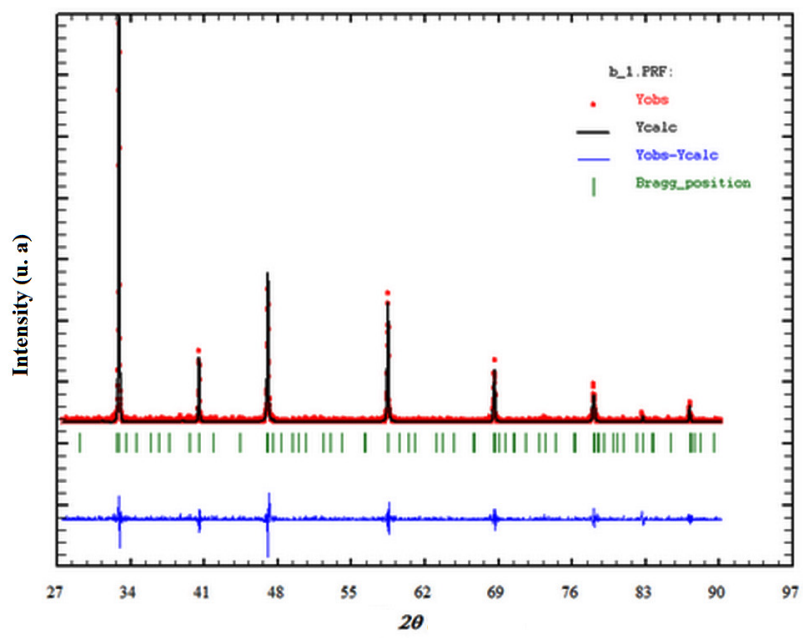

Fig.1a XRD patterns of $\left(\mathrm{Ca}_{\mathrm{x}} \mathrm{Sr}_{1-\mathrm{x}}\right) \mathrm{TiO}_{3}$ ceramics: $\mathrm{x}=0.2$ and 0.4 ; Fig.1b Rietveld analysis of the $\mathrm{Ca}_{0.2} \mathrm{Sr}_{0.8} \mathrm{TiO}_{3}$, Peak position and the differences between observed and calculated profiles are shown.
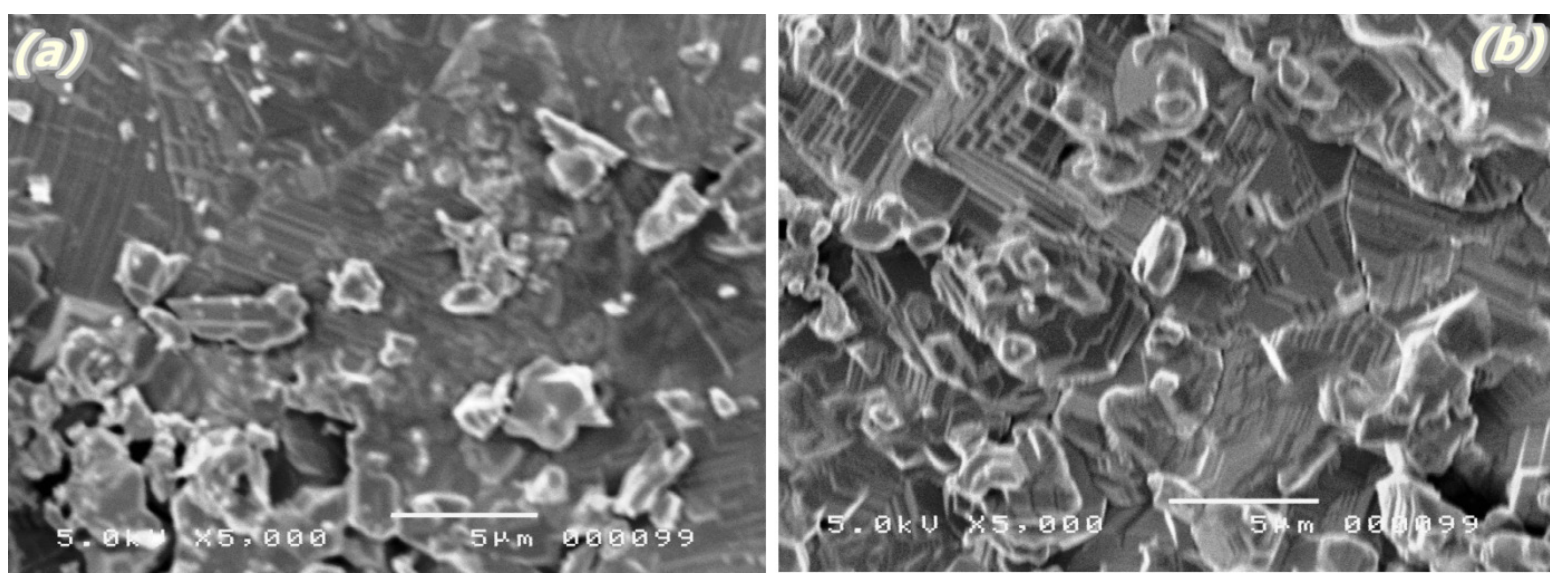

Fig.2. SEM photographs of the samples sintered at $1300{ }^{\circ} \mathrm{C}$ for $3 \mathrm{~h}$ : (a) $\mathrm{Ca}_{0.2} \mathrm{Sr}_{0.8} \mathrm{TiO}_{3}$ and $\mathrm{Ca}_{0.4} \mathrm{Sr}_{0.6} \mathrm{TiO}_{3}$.

\subsection{Electrical and dielectric characterization in air}

Fig.3(a-b) shows an example of an Nyquist Plot of $\mathrm{C}_{0.4} \mathrm{ST}$ measured at a range temperatures from $250^{\circ} \mathrm{C}$ to 
$800^{\circ} \mathrm{C}$. The Nyquist Plot at temperatures between $250^{\circ} \mathrm{C}$ and $400^{\circ} \mathrm{C}$ is characterized by the appearance of a small oblique line at low frequency attributed to the response of the electrode followed by semicircular arcs related to the response of the grain in the high frequency domain. At high frequencies the semi-circle is characterized by a parallel combination of a resistor $\mathrm{R}$ and a volume capacity $\mathrm{C}$, while at low frequencies the straight line represents a capacitive effect on the interface electrode-electrolyte. This effect is referred to as double layer capacitance $(\mathrm{Cdl})^{[6,7]}$. The variation of impedance spectrum as function of temperature showed that only one depressed arc clearly observed at the temperature range from 250 to $400^{\circ} \mathrm{C}$ which indicate the presence of single electrical relaxation phenomena due to the statistical distribution of relaxation times ${ }^{[8,9]}$. As shown in Fig.3b the complex impedance spectrum of CST was measured at temperatures from $550^{\circ} \mathrm{C}$ to $700^{\circ} \mathrm{C}$ and comprises two semicircular arcs attributed to grain and grain boundary contributions. The contribution of high and intermediate frequencies arcs are superposed. These semicircles can be represented by an equivalent circuit with two parallel RC elements arranged in series. Fig. $3 \mathbf{c}$ shows the variation of the ac conductivity $\left(\sigma_{\text {ac }}\right)$ versus frequency at different temperatures. From these figures, it can be concluded that the variation of conductivity versus frequency shows four distinct regimes within the measured frequency window limit:i) two plateaus and ii) two asymptotic regimes ${ }^{[10,11]}$. In order to fitting the dispersion region of the ac conductivity the Jonscher's law ${ }^{[12]}$ was used the following equation:

$$
\sigma_{\mathrm{ac}}=\sigma_{\mathrm{dc}}+\mathrm{A} \omega^{\mathrm{n} 1}+\mathrm{B} \omega^{\mathrm{n} 2}
$$

where $A$ and $B$ are temperature-dependent constants, both $n_{1}(T)$ and $n_{2}(T)$ are two almost temperatureindependent parameters and are close to unity, and $\sigma_{\mathrm{dc}}$ is the static conductivity. The conductivity in the plateau region ("stationary regimes") (low frequency region $\mathrm{f}<1000 \mathrm{~Hz}$ and in the intermediate frequency region) is virtually constant and independent of frequency. This region corresponds to the static conductivity which increases with temperature and is due to the disorder of cations between neighboring sites ${ }^{[13]}$. In the $\left(10^{3} \mathrm{~Hz}<\mathrm{f}<10^{4} \mathrm{~Hz}\right)$ frequency region ("asymptotic regimes"), the variation of conductivity us function of frequency is due to the polarization effects between electrode- electrolyte interfaces ${ }^{[13]}$.It is observed that the high frequency region ("asymptotic regimes") is closer to the relaxation times and the mobility of the charge carriers is high, therefore, the conductivity increases with frequency ${ }^{[13,14]}$.
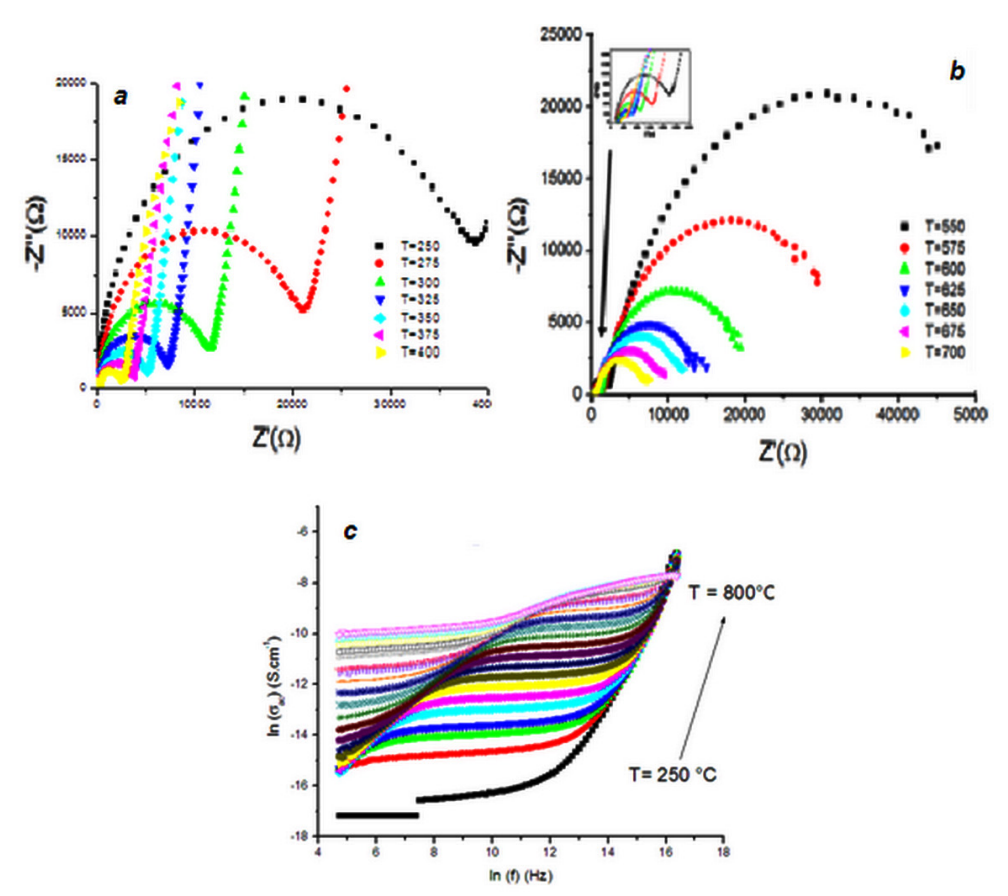

Fig.3(a-b) Impedance spectra (Z" vs. Z') and AC conductivity; Fig. 3c plots of the $\mathrm{Ca}_{\mathrm{x}} \mathrm{Sr}_{1-\mathrm{x}} \mathrm{TiO}_{3}$ samples at various temperatures. 
Activation energies (Ea) for the conduction process were extracted to the conductivity data of the Arrhenius relation using the equation below ${ }^{[15,16]}$ :

$$
\sigma \mathrm{T}=\mathrm{A}_{0} \exp \left(-\mathrm{E}_{\mathrm{a}} / \mathrm{KT}\right)
$$

where $\mathrm{T}, \sigma, \mathrm{A}_{0}, \mathrm{~K}$ and $\mathrm{E}_{\mathrm{a}}$ are the absolute temperature, conductivity, pre-exponential factor, Boltzmann constant and activation energy, respectively. Fig. 4 display the variation of $\log \sigma \mathrm{T}$ vs $1000 / \mathrm{T}$ for the total conductivity, the grain interior and the grain boundary conductivities of the $\mathrm{Ca}_{0.2} \mathrm{Sr}_{0.8} \mathrm{TiO}_{3}$ and $\mathrm{Ca}_{0.4} \mathrm{Sr}_{0.6} \mathrm{TiO}_{3}$ samples sintered at $1300^{\circ} \mathrm{C}$. At $475^{\circ} \mathrm{C}$, the calculated total conductivity of the strontium calcium titanate sample is $1.21 \times 10^{-4} \mathrm{~S} . c m^{-1}$ for $\mathrm{x}=0.2$ and $1.26 \times 10^{-4}{\mathrm{~S} . \mathrm{cm}^{-1}}^{-}$for $\mathrm{x}=0.4$ at $600^{\circ} \mathrm{C}$. The activation energy is calculated from the slope of the $\log \sigma \mathrm{T}$ vs $1000 / \mathrm{T}$ plot and it is found to be 1.03 and $0.79 \mathrm{eV}$ for $\mathrm{x}=0.2$ and 0.4 respectively for the total conductivity. It is clear that the value of the activation energy decreases with an increase in Ca content. The low activation energy value may be due to the ionized oxygen vacancies. However, the decrease in activation energy at higher temperatures is due to the attractive interaction between the dopant cations and oxygen vacancies. The $\sigma_{\mathrm{dc}}$ values for the compounds at each temperature can be directly obtained from the conductivity data shown in Fig.3c, as the conductivity value in the low frequency plateau (dc plateau) and the static conductivity, $\sigma \mathrm{dc}$, increase with the variation of temperature, and this indicates the thermally activated process of electrical conduction in the material. The activation energy value estimated from the Arrhenius plot of $\sigma_{\mathrm{dc}} \mathrm{with}$ respect to $10^{3} /$ $\mathrm{T}$ is $1.23 \mathrm{eV}$ and $0.63 \mathrm{eV}$ for $\mathrm{Ca}_{0.2} \mathrm{Sr}_{0.8} \mathrm{TiO}_{3}$ and $\mathrm{Ca}_{0.4} \mathrm{Sr}_{0.6} \mathrm{TiO}_{3}$, respectivelyatseveral temperatures between 648 and 923K (Fig. 4d).
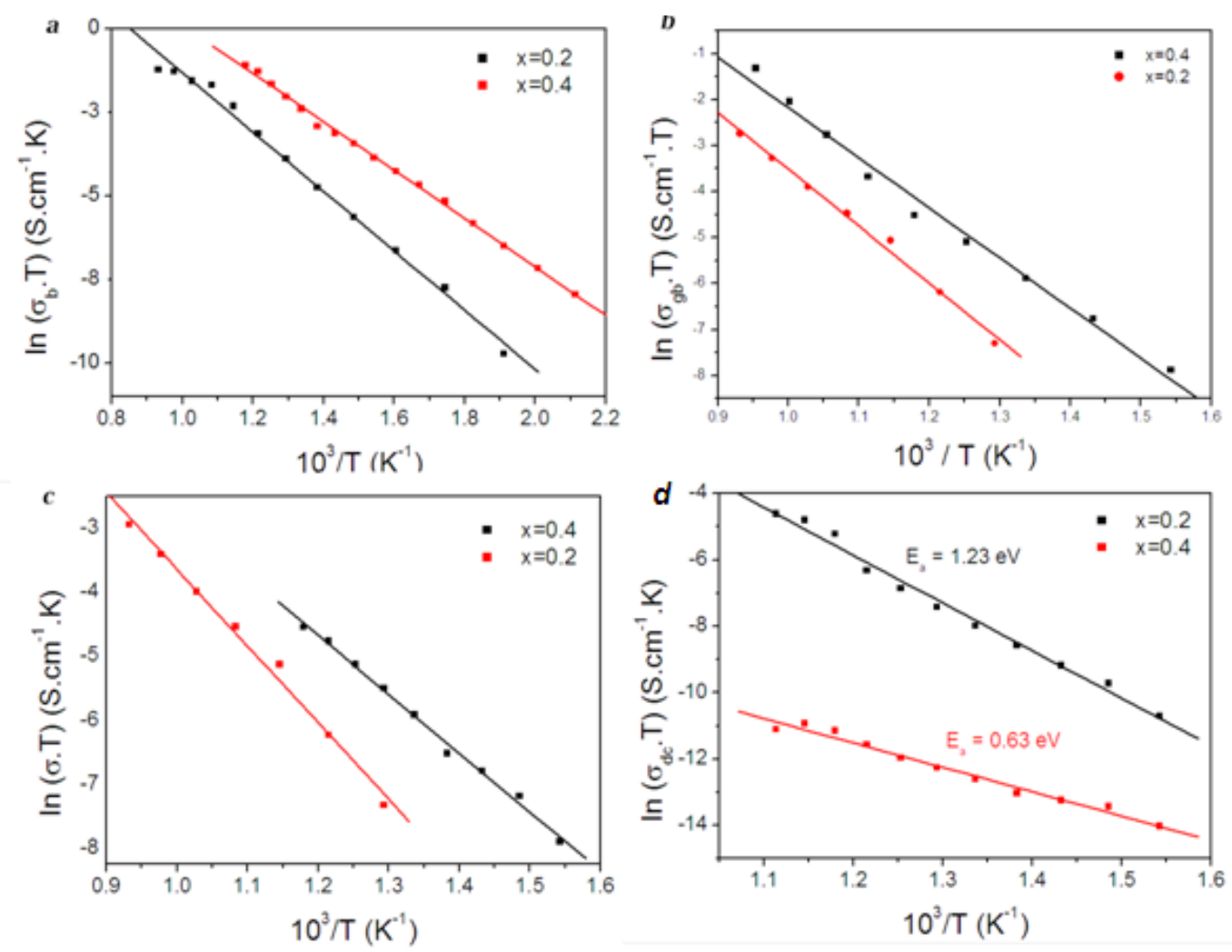

Fig.4. Arrhenius plot of (a) grain, (b) grain boundary, (c) total electrical conductivity and (d) dc conductivity obtained for the CST $(x=0.2$ and 0.4$)$ anode sintered at $1300^{\circ} \mathrm{C}$.

Fig. 5a and $\mathbf{d}$ show the real part of the dielectric permittivity vs $\log \omega$ for the compositions of the CST at several temperatures between $250^{\circ} \mathrm{C}$ and $800^{\circ} \mathrm{C}$. These were calculated from the measured impedance data, Z' \& Z', and the pellet dimensions. The variation of the $\varepsilon^{\prime}$ as a function of angular frequency in the $250^{\circ} \mathrm{C}$ 
$-500^{\circ} \mathrm{C}$ temperature range (Fig. 5a) has been observed to decrease with increasing frequency and attains a constant value at high frequencies. At high frequencies, $\varepsilon$ ' remains constant; this is due to a rapid polarization processes with no ionic motion contribution. At lower frequencies the variation of the dielectric constant $\varepsilon^{\prime}$ indicates a dispersive behavior due to the contribution of polarization arising from the charge accumulation at the interface and leads to the polarization of the ionic materialwhich results in the formation of a space charge region at the electrode-electrolyte interface ${ }^{[17,18]}$. The value of the dielectric constant $\varepsilon^{\prime}$ increases with increasing temperature. For intermediate frequencies it has been observed that the plateau region (Fig. 5b) is shifted towards higher frequencies with increasing temperature. The loss tangent $(\delta)$ varies with angular frequency at selected temperatures between $250^{\circ} \mathrm{C}$ and $675^{\circ} \mathrm{C}$, as shown in Fig.5c. Loss peaks are observed to move towards higher frequencies when increasing the temperature. These peaks suggest a dielectric relaxation phenomenon in the material. Generally, the dielectric losses can be provoked by charge defects. At lower frequencies these peaks can be attributed to the contribution of all the grain boundaries. In Fig.5d two peaks are observed and shift towards higher frequencies with temperature. This can be attributed to the gradual decrease inresistance with increasing frequency. At lower frequencies these peaks can be attributed to the contribution of all the grain boundaries, but at high frequencies these peaks are attributed to the contribution of the grains ${ }^{[19,20]}$.
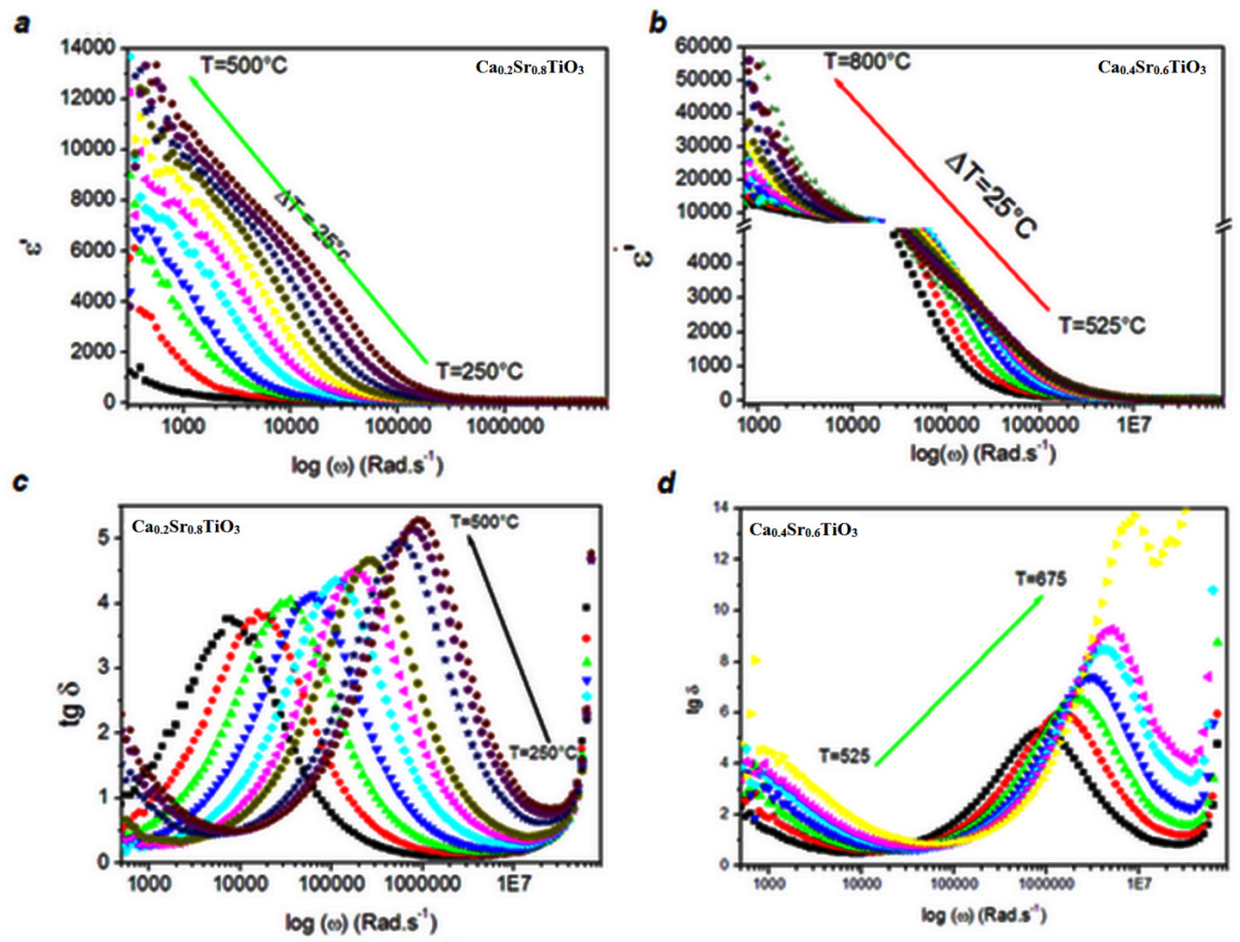

Fig.5(a-b) Electric permittivity plots ( $\varepsilon^{\prime}$ vs $\left.\log \omega\right)$ and Fig.5(c-d) the variation of tan $\delta$ with angular frequency obtained at various temperatures for the CST samples.

\section{CONCLUSION}

Calcium strontium titanates $\mathrm{Ca}_{\mathrm{x}} \mathrm{Sr}_{1-\mathrm{x}} \mathrm{TiO}_{3}(\mathrm{x}=0.2$ and 0.4$)$ were synthesized via the solid state method. The samples obtained show a perovskite structure that changes from quadratic to orthorhombic. Increasing the temperature the contributions attributed to the bulk and grain boundary response were observed, as well as temperature-dependent relaxation. At $475^{\circ} \mathrm{C}$ for $\mathrm{x}=0.2$ and $600^{\circ} \mathrm{C}$ for $\mathrm{x}=0.4$, the best conductivities for the CST pellet are $1.21 \times 10^{-4} \mathrm{~S} . c m^{-1}$ and $1.26 \times 10^{-4}{\mathrm{~S} . \mathrm{cm}^{-1}}^{-1}$ respectively. The CST conduction activation energy is calculated to be $0.79 \mathrm{eV}$ for $\mathrm{x}=0.4$ and $1.03 \mathrm{eV}$ for $\mathrm{x}=0.2$ in the $500-700^{\circ} \mathrm{C}$ temperature range. In view of the above, CST can be considered as a anode material for SOFCs, but its conductivity needs to be improved. 


\section{Acknowledgements}

This work was supported by the Ministry of Higher Education and Scientific Research of Tunisia. The author would also like to thank the language expert Nayua Abdelkefi for proofreading the manuscript.

\section{Conflict of Interest}

The authors declare that they have no conflict of interest.

\section{REFERENCES}

[1] M.Q. Nguyen J. Am. Ceram.Soc.76 (3) (1993) 563.

[2] D.P. Fagg, V.V. Kharton, J. R. Frade, A. A. L. Ferreira, Stability and mixedionic electronic conductivity of $(\mathrm{Sr}, \mathrm{La})(\mathrm{Ti}, \mathrm{Fe}) \mathrm{O} 3$ _d perovskites, Solid StateIonics156(2003)45-57.

[3] F. Gao, H. L. Zhao, X. Li, et al., Preparation and electrical properties of yttrium doped strontium titanate with B-site deficiency, Journal of Power Sources185(2008)26-31.

[4] QunHui, J. Phys: Condens. Matter 19 (11pp) (2007) 335214.

[5] M. Kahlaoui, A. Inoubli , S. Chefi, A. Madani,C. Chefi, Ionics 20 (2014) 1729-1735

[6] H. X. Zhang, C. H. Kam, Y. Zhou, X. Q. Han, S. Buddhudu, Q. Xiang, Y. L. Lam, Y. C. Chan, Appl. Phys. Lett. 77 (2000) 609.

[7] A. Gedanken, R. Reisfeld, L. Sominski, Z. Zhong, Y. Koltypin, G. Panczer, M. Gaft, H. Minti, Appl. Phys. Lett. 77, (2000) 945.

[8] R.J. Grant, M.D. Ingram, L.D.S. Turner, C.A. Vincent, J. Phys.Chem. 82 (1978) 2838.

[9] J.R. Macdonald, Impedance Spectroscopy, Wiley, New York, 1987.

[10] X. Li, H. Zhao, W. Shen, F. Gao, X. Huang, Y. Li, Z. Zhu, J. Power Sources 166 (2007) 47-52.

[11] A. Shukla, R.N.P.Choudhary, Physica B 406 (2011) 2492-2500.

[12] A.K. Joncher: a) Nature, 256 (1977) 673, b) J.Mater.Sci., 16 (1981) 2037.

[13] J. Kawamura, S. Rikito, M. Shinya, M. Shimoji, Solid State Ionics 25 (1987) 155.

[14] M.C.R. Sastry, K.J. Rao, Solid State Ionics 44 (1991) 187.

[15] Y. Li, J.H. Gong, Z.L. Tang, Y.S. Xie, Temperature-independent activation energy for ionic conduction of zirconia based solid electrolytes, ActaPhysico-ChimicaSinica 17 (2001) 792-796.

[16] J.A. Kilner, B.C.H. Steele, in: O.T. Sorensen (Ed.), Nonstoichiometric Oxides, Academic Press, New York, p. 2331981.

[17] G.C. Psarras, E. Manolakaki, G.M. Tsangaris, Composites A 34 (2003) 1187.

[18] K.P. Chandra, R.N. Gupta, Int. J. Mod. Phys. B 22 (2008) 2321.

[19] Li M, Feteira A and Sinclair D C J. Appl. Phys, 105 (2009). 114109.

[20] Wang C-C, Zhang M-N, Xu K-B and Wang G-J J. Appl. Phys.112(2012) 034109 